\title{
Content validity of the nursing diagnostic Breathing Pattern, Ineffective, in children with congenital heart defects
}

\author{
Validade de conteúdo do diagnóstico de enfermagem Padrão Respiratório Ineficaz em crianças com cardiopatias congênitas
}

Validez de contenido del diagnóstico de enfermería Estándar Respiratoria Ineficaz en niños con cardiopatías congénitas

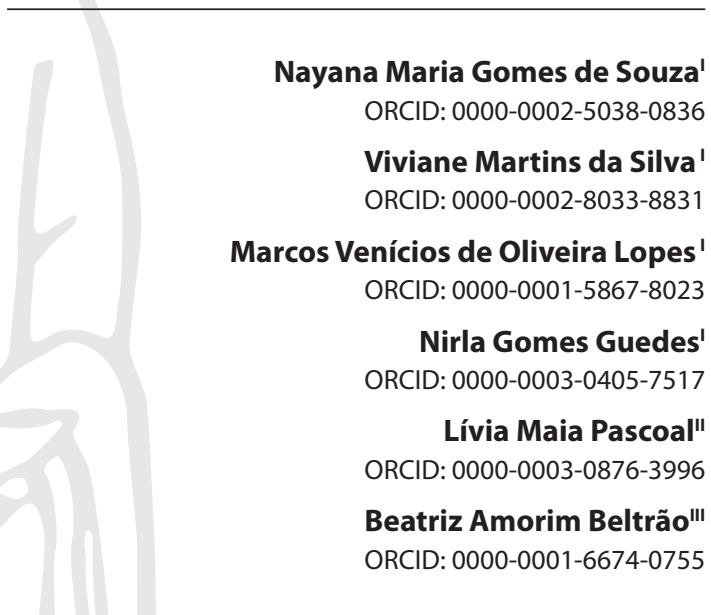

'Universidade Federal do Ceará. Fortaleza, Ceará, Brazil. "Universidade Federal do Maranhão. Imperatriz, Maranhão, Brazil.

"' Universidade Federal do Ceará, Hospital Universitário Walter Cantídio. Fortaleza, Ceará, Brazil.

How to cite this article: Souza NMG, Silva VM, Lopes MVO, Guedes NG, Pascoal LM, Beltrão BA. Content validity of the nursing diagnostic Breathing Pattern, Ineffective, in children with congenital heart defects. Rev Bras Enferm. 2021;74(Suppl 4):e20190844. doi: http://dx.doi.org/10.1590/0034-7167-2019-0844

Corresponding author: Nayana Maria Gomes de Souza E-mail: nayanamgs@hotmail.com

EDITOR IN CHIEF: Dulce Barbosa ASSOCIATE EDITOR: Marcos Brandão

Submission: 03-09-2020

Approval: 11-01-2020

\section{ABSTRACT}

Objective: To estimate the content validity of the nursing diagnostic Breathing Pattern Ineffective, in children with congenital heart defects. Method: Methodological study in two stages: 1) integrative literature review; 2) content validation, with 23 nurses. An instrument with 10 related factors and 21 defining characteristics for data collection was used. The analysis by the evaluators was carried out using the relevance criteria. The Content Validity Index was used. Valid results were those above 0.9 with a Wilcoxon test above 0.05 . Results: The final proposal incorporates nine from the ten causal factors. From them, five do not belong in the NANDA-I list. Regarding the defining characteristics, they were all considered to be relevant, and five are not among the list of signs and symptoms of the NANDA-I taxonomy. Conclusion: The findings of this study include specific elements of the pediatric population with congenital heart defect which are not present in the structure of the diagnostic being studied.

Descriptors: Nursing Diagnosis; Nursing Process; Nursing Research; Validation Studies; Congenital Heart Defects.

\section{RESUMO}

Objetivo: Estimar a validade de conteúdo do diagnóstico de enfermagem Padrão Respiratório Ineficaz em crianças com cardiopatias congênitas. Métodos: Estudo metodológico realizado em duas etapas: 1) revisão integrativa da literatura; 2) validade do conteúdo, com 23 enfermeiros. Utilizou-se instrumento contendo 10 fatores relacionados e 21 características definidoras para coleta de dados. Os juízes realizaram a análise com base no critério de relevância. Foi utilizado o Índice de Validade de Conteúdo diagnóstico, considerado válido se superior a 0,9 e se teste de Wilcoxon maior que 0,05 . Resultados: A proposta final incorpora nove dos dez fatores causais. Deles, cinco não pertencem à lista da NANDA-I. Quanto às características definidoras, todas foram consideradas relevantes, e cinco não pertencem ao rol de sinais e sintomas da taxonomia NANDA-I. Conclusão: Os achados deste estudo incluem elementos específicos da população pediátrica com cardiopatia congênita que não estão presentes na estrutura do diagnóstico em estudo.

Descritores: Diagnóstico de Enfermagem; Processos de Enfermagem; Pesquisa em Enfermagem; Estudos de Validação; Cardiopatias Congênitas.

\section{RESUMEN}

Objetivo: Estimar validez de contenido del diagnóstico de enfermería Estándar Respiratoria Ineficaz en niños con cardiopatías congénitas. Métodos: Estudio metodológico realizado en dos etapas: 1) revisión integrativa de literatura; 2) validez del contenido, con 23 enfermeros. Utilizó instrumento conteniendo 10 factores relacionados y 21 características definidoras para recogida de datos. Jueces realizaron el análisis con base en criterio de relevancia. Utilizado Índice de Validez de Contenido diagnóstico, considerado válido si superior a 0,9 y si test de Wilcoxon mayor que 0,05 . Resultados: Propuesta final incorpora nueve de los diez factores causales. De ellos, cinco no pertenecen a la lista de la NANDA-I. Cuanto a características definidoras, todas han consideradas relevantes, y cinco no pertenecen al rol de señales y síntomas de la taxonomía NANDA-I. Conclusión: Los hallados de esto estudio incluyen elementos específicos de población pediátrica con cardiopatía congénita que no están presentes en la estructura del diagnóstico en estudio.

Descriptores: Diagnóstico de Enfermería; Procesos de Enfermería; Investigación en Enfermería; Estudios de Validez; Cardiopatías Congénitas. 


\section{INTRODUCTION}

Although there are many classifications and types of congenital heart defects (CHD), which vary in severity and complications, children with CHD frequently present physiopathological defects, such as: altered lung blood flow, cyanosis, lung hypertension, and ventilation perfusion mismatch ${ }^{(1)}$. These factors contribute for the appearance of signs and symptoms that are characteristic of the respiratory nursing diagnostics ${ }^{(2)}$. The diagnostic "Breathing Pattern, Ineffective" (BPI), present in the taxonomy from NANDA International, Inc. (NANDA-I), is an example, since it is directly associated to the ventilation process ${ }^{(3)}$.

Studies about the accuracy of the characteristics that determine a BPI diagnostic in children and adolescents with congenital heart defects showed a prevalence that varied from $26.8 \%$ to $86 \%{ }^{(4-5)}$. Therefore, the evaluation of the clinical signs and symptoms and of the causes of the diagnostic of the patient is essential to carry out precise inferences, directing the planning of nursing actions and quickly reverting this condition, preventing other respiratory defects.

In the specific literature about the pediatric population with congenital heart defect, there are studies that address causal factors, that is, conditions that exist prior to the nursing diagnostic (related factors, risk population and associated conditions), and characteristics that define the nursing diagnostic of BPI that are not described in NANDA-I, but are often identified in clinical practice ${ }^{(5-8)}$. Although there is scientific evidence that point at the relation of other components with the BPI diagnostic, they are yet to be considered as elements of said diagnostic.

The absence of these elements in the system of classification can interfere in diagnostic inference and determination, since components that have some regular relation with the nursing diagnostic (ND) may generate date that help nurses to examine how do the evidence fit with the phenomenon, and their inclusion as diagnostic elements is recommended ${ }^{(9)}$. This gap may result in a low adherence to the taxonomy during nursing clinical practice, since a tool without it would not offer an adequate support for the varied and complex situations the nurse may deal with in the course of caring for the patient.

The researches carried out so far focused only on the clinical validation of the defining characteristics that are contained in the BPI diagnostic in children with congenital heart defects ${ }^{(4-6)}$. These studies are important for advancing the knowledge about BPI in the target-population, but they offer a fragmented view of this diagnostic, since their analysis was carried out considering only the defining characteristics. Therefore, it is also necessary to analyze the causes of the diagnoses, that is, the factors that cause of BPI, aiming to diminish uncertainties that may become apparent during the inference of the diagnostic.

Among the procedures required to validated a ND are the evidence of content validity, an alternative to minimize structural gaps that prejudice the diagnostic reasoning of nurses ${ }^{(3)}$. However, there are limitations in the choice of this method, especially with regard to the experience of the evaluators and to the evaluation of their opinions.

An approach that may diminish these limitations is the Diversity Prediction Theorem, which advocates that the collective knowledge leads to better results than the individual knowledge, even when the latter includes high-level specialists ${ }^{(10)}$. For this approach, the more diverse is the experience of the evaluators, the more precise will the estimates be, about the data obtained to validate the content of the nursing diagnostic.

Consequently, the need to analyze the components of the BPI stands out, as well as that to relate them to the clinical features of children with congenital heart defects, and to submit BPI components to the evaluation of experts, including potential future components and those already approved by NANDA-I. This type of study investigates the relation between the occurrence of the diagnostic and of its components, while also corroborating the findings already identified, increasing the level of evidence and facilitating the diagnostic inference made by the nurse.

Furthermore, these researches may help to effectively establish, the nursing results and interventions related to the diagnostic being studied, building a more consistent diagnostic structure with all elements that make up the diagnostic. This approach can increase the efficacy of the identification and triage of children with congenital cardiac diseases with a high probability of developing an ineffective breathing pattern.

\section{OBJECTIVE}

To estimate the content validity of the nursing diagnostic "Breathing Pattern, Ineffective" (BPI), in children with congenital heart defects ${ }^{(2)}$.

\section{METHODS}

\section{Ethical aspects}

With regard to the ethical aspects of scientific research, this study was submitted and approved on September 1st, 2017, by the Research Ethics Committee of the Universidade Federal do Ceará, according to the recommendations of Resolution 466, on December 12th, 2012(2).

\section{Design, and period of study}

This is a methodological study guided by the SPIRIT tool, carried out in two stages: 1 ) integrative literature review, with causal factors and the defining characteristics of the BPI in children with CHD; 2 ) evidence of the validity of the content of the diagnosis, based on the Diversity Prediction Theorem ${ }^{(10)}$. The period of data collection took place from September to November $2017^{(2)}$.

\section{Stage 1 - Integrative revision of literature}

At first, an integrative review of literature was developed, extracting data from four databases (PUBMED, CINAHL, Web of Science and Scopus) through the use of the descriptors "pulmonary ventilation", "respiration", and "heart disease, congenital", associated through the boolean operator "AND"(2). The guiding question of the review was: What are the components associated to the manifestation of the nursing diagnosis "Breathing Pattern, Ineffective", in children with congenital heart defects who did not undergo total corrections ${ }^{(2)}$ ? 
The criteria to include the articles in this stage included: original articles; presenting, in their results, causal factors, as well as signs and symptoms of the BPI diagnosis in children with CHD; with abstracts available in the databases; in English, Portuguese, or Spanish. There was no restriction regarding the year of publication. The exclusion criteria included: works presented in congresses, dissertations, monographs, theses, letters to the editor, and reflection studies ${ }^{(2)}$.

To guarantee the quality of this stage and avoid selection biases, all studies were verified by two reviewers, independently. The inclusion or not of each article was decided upon a reading of the title and the abstract. In the case of disagreements between the two reviewers, a third one participated. The articles that, at first, were unavailable in the databases, were found in-full through the platform of the Coordination for the Improvement of Higher Education Personnel (CAPES). All studies selected were read in full to guarantee that the inclusion criteria were indeed attended.

The extraction of data from the articles selected was carried out using an instrument that contained descriptive variables from the publications, including data such as: authors, year of publication, journal, database, country of the study, and identification of the components of the nursing diagnostic (causal factors and defining features) of the BPI in children with congenital heart defects. The causal factors taken into account were clinical conditions or events that preceded the BPI; with regard to its defining features, clinical conditions or events that resulted from the diagnosis were taken into account.

After the findings of this review, a group of nurses analyzed causal factors and the defining characteristics in the stage of data extraction, searching for a consensus about which components represented a manifestation of $\mathrm{BPI}$. As a result, 50 articles were found, which evidenced 10 causal factors and 21 characteristics that define the BPI diagnosis.

The ten causing factors found were classified as: Related factors (position of the body inhibiting pulmonary expansion, anxiety, pain, and physical efforts), Associated conditions (deformities in the wall of the thorax, increased resistance of air passages, reduction in pulmonary complacency, increased concentration of carbon dioxide, increased hydrogen concentration), and Risk population (age below 2 years old) ${ }^{(2)}$. It stands out that NANDA-I mentions, in its taxonomy, causal factors that were not included for this validation due to their etiologic course, since they are not directly associated to congenital heart defects.

In the review mentioned above, 21 defining characteristics were also found, among which 16 were in the taxonomy under study and 5 were not in the list of defining characteristics at NANDA-I, namely: hypoxia, hypoxemia, cyanosis, sleep-disordered breathing, fatigue of respiratory muscles ${ }^{(2)}$.

\section{Stage 2 - Evidence of the validity of the diagnosis content}

In the integrative review, after the identification of the components of the diagnosis Breathing Pattern, Ineffective, in children with congenital heart defects, the next stage was the content validation, aimed at verifying, with the evaluators, the relevance of the causal factors and of the defining characteristics surveyed ${ }^{(2)}$.
The evaluators judged the relevance of each component (causal factors and defining characteristics) identified in the review. Relevance here refers to the capacity of the item of being consistent with the attribute defined and with other expressions that relate to the same attribute ${ }^{(11)}$.

\section{Population; criteria of inclusion and exclusion}

The criteria of inclusion for this stage were: nurses with practical experience, as determined by how long they have worked with children with congenital heart defects; nurses with scholar experience, determined by how long they participated in research groups about the theme "nursing diagnoses and/or congenital heart defects"(2). As a result, the combination of practical abilities and scientific experiences can use pondered judgments to reach more consistent estimates according to the Diversity Prediction Theorem.

The evaluators were selected according to their curricula in the Lattes Platform, from the CNPq website, and the sampling strategy used was of the "snowball" type. Among the 39 evaluators selected, only 23 accepted participating in the study, and the data collection instrument sent was returned in up to 45 days after they received $i t^{(2)}$.

\section{Study protocol}

An invitation was sent through email to the nurses, offering information about the objective of the research, the methods it adopted, and the availability for participating in the study. After they agreed to participate, the evaluators received, also via email, the Free and Informed Consent Form and the research questionnaire ${ }^{(2)}$.

The instrument employed in similar results was adapted ${ }^{(12-13)}$ and divided in two parts: one, made up by the characterization of evaluators; and another, related to the components of the nursing diagnostic "Breathing Pattern, Ineffective", found in the literature revision ${ }^{(2)}$. Each evaluator indicated whether the marker of the component was relevant through a negative (0) or affirmative (1) answer. When the answers were negative, the components were altered and/or excluded, according to the suggestion of the evaluators.

\section{Analysis of results and statistics}

After data collection was finished, the level of expertise in nursing of the evaluators was classified according to the criteria established by Benner, Tanner, and Chesla ${ }^{(14)}$ : beginner, advanced beginner, competent nurse, proficient nurse, and expert nurse. The criteria considered for this classification are described in Table 1.

The level of expertise of the evaluators was defined according to a simple mean of the score obtained using the criteria: time of practice, time in a research group, and scientific knowledge. The last criterion was established by the sum of subclassifications, including the academic level, the theme of the academic work, and scientific production in ND and/or $\mathrm{CHD}^{(2)}$.

The results varied within a score from 1 (beginner) to 5 (expert). This expertise criteria are pertinent to find evaluators from a diversity 
of profiles, thus minimizing the biases during content analysis, in accordance to the Diversity Prediction Theorem, in which the global judgment of a group of evaluators whose levels of knowledge are varied are more precise in the analysis of a construct ${ }^{(15)}$.

Table 1 - Parameters to classify the evaluators with regard to their level of expertise, according to Benner, Tanner, and Chesla (2009) ${ }^{(2)}$

\begin{tabular}{cccccc}
\hline & \multicolumn{2}{c}{ Clinical experience } & \multicolumn{3}{c}{ Academic experience } \\
Score & $\begin{array}{c}\text { Time in } \\
\text { time of } \\
\text { practice } \\
(\mathbf{X})\end{array}$ & $\begin{array}{c}\text { Scientific knowledge }(\mathbf{Z}) \\
\text { research } \\
\text { groups*+ } \\
(\mathbf{Y})\end{array}$ & $\begin{array}{c}\text { Regrees } \\
\left(\mathbf{Z}_{\mathbf{1}}\right)\end{array}$ & $\begin{array}{c}\text { Research } \\
\text { made for } \\
\text { degrees }\left(\mathbf{Z}_{\mathbf{2}}\right)\end{array}$ & $\begin{array}{c}\text { Articles } \\
\text { published } \\
\left(\mathbf{Z}_{\mathbf{3}}\right)\end{array}$ \\
\hline 0 & - & - & Graduated & No & No \\
1 & $1-5$ & $1-3$ & Specialist & Yes & Yes \\
2 & $6-8$ & $4-6$ & Master & - & - \\
3 & $9-11$ & $7-9$ & PhD & - & - \\
4 & $12-15$ & $10-12$ & - & - & - \\
5 & 16 or more & 13 or more & - & - & - \\
\hline
\end{tabular}

Note: *In years; + Intervals established based on the times of practice and on the research group (minimum and maximum) presented by the evaluators.

Level of expertise: sum of the score from the columns $X, Y$, and $Z$, divided by $3^{(2)}$

Data was organized in a spreadsheet in Microsoft Office Excel 2016 and analyzed using the statistical program $R$, version 3.2.0. The characterization of the evaluators was carried out through a descriptive analysis that included absolute and relative frequencies, with a confidence interval of $95 \%{ }^{(2)}$. The Shapiro-Wilk test was used to verify whether the sample had a normal distribution.

For the content validity analysis of the components of the $\mathrm{BPI}$ diagnosis, the content validity index (CVI) was calculated according to the model of predictive diversity, in which the evaluation of the evaluators is pondered according to their level of expertise ${ }^{(2)}$. In this case, pondered estimates of the mean and median of evaluations were calculated. The CVI was estimated by the pondered median because the distribution of the estimates was found not to be within normality ${ }^{(2)}$. In addition to the estimates of CVI medians, the confidence intervals of $95 \%$ were also calculated for each median, and the Wilcoxon test was applied for pondered medians ${ }^{(2)}$. Its reference value for the null hypotheses was a CVI of 0.9 or greater. Therefore, an item was considered valid for the BPI diagnostic when its descriptive level ( $p$-value) was higher than $0.05^{(2)}$. The statistical $\mathrm{S}$ was used to measure the global agreement between evaluators about the relevance of the components of the nursing diagnosis ${ }^{(16)}$. There were separate analyses for defining characteristics and causal factors.

\section{RESULTS}

From the evaluators that made up the final sample, 11 were nurses with experience in research about nursing languages; 12 nurses had practice in caring for children with congenital heart defects. The rate of return of the instruments was $58.97 \%$ (2).

The sample of evaluators included participants from 25 to 40 years old, with a median of $32(I I Q \pm 6)$. Regarding the time of professional formation, the participants had a median of nine years (IIQ \pm 5 ). Most were female $(95.7 \%)$, had a master's degree $(52.2 \%)$ and were from the Northeast region (91.2\%). Regarding current jobs, it was found that $24.7 \%$ of the sample were nurses working in health care; $17.4 \%$ were nursing graduation professors; and $17.4 \%$ were undergoing post-graduation courses in Nursing.

Regarding the use of the nursing diagnosis, most of the sample stated to use it in their clinical practice $(95.6 \%)$ and in teaching (60.9\%). Regarding their research activities, $60.9 \%$ of evaluators stated to develop studies on nursing terminologies; among them, $43.4 \%$ are related to the diagnostic "Breathing Pattern, Ineffective", and $65.2 \%$ with congenital heart defects. Still, most participants were in a study group about nursing terminologies (56.5\%). Another factor that should be highlighted is that a high number of evaluators (75\%) mentioned to work in nursing assistance with patients with a BPI diagnosis and/or congenital heart defects $^{(2)}$. According to the classification of nursing expertise, $52 \%$ of evaluators presented a level of competent, proficient, or expert nurse ${ }^{(2)}$.

Data from Table 2 show the judgment with regard to causal factors mentioned in the integrative review of BPI nursing diagnoses in children with heart defects ${ }^{(2)}$. These were mentioned to be relevant. The final list included those who presented CVI of 0.9 or higher in the evaluation.

According to the data in Table 2, nine out of the ten causal factors expressed CVI $>0.9$. They were: increased resistance of the air passages, reduction of pulmonary complacency, increased carbon dioxide concentration, increased hydrogen concentration, thoracic wall deformities, position of the body inhibiting pulmonary expansion, physical effort, anxiety, and pain ${ }^{(2)}$.

Because the risk population "Age below 2 years old" showed no statistical significance, that is, CVI above 0.9 , it was excluded from the list proposed of causal factors of the diagnostic of BPI. The results of the $S$ statistic found $(0.74)$ showed a good agreement with the evaluation of evaluators.

Below, Table 3 includes the CVIs obtained by the evaluators with regard to the relevance of clinical indicators.
Table 2 - Analysis by the evaluators of the relevance of causal factors of the nursing diagnosis "Breathing Pattern, Ineffective" ( $\mathrm{n}=23)$, Fortaleza, Ceará, Brazil, 2019(2)

\begin{tabular}{|c|c|c|c|c|c|}
\hline \multirow{2}{*}{$\begin{array}{l}\text { Variables } \\
\text { Causal factors }\end{array}$} & \multicolumn{4}{|c|}{ Relevance } & \multirow[b]{2}{*}{ Value** } \\
\hline & $p$ value* & CVI & & $5 \%$ & \\
\hline \multicolumn{6}{|l|}{ Associated conditions } \\
\hline Increase in the resistance of air passages & -- & 1.00 & -- & -- & 1.000 \\
\hline Reduction of pulmonary complacency & -- & 1.00 & -- & -- & 1.000 \\
\hline Increased concentration of carbon dioxide & $<0.001$ & 1.00 & 1.00 & 1.00 & 1.000 \\
\hline Increased concentration of hydrogen & $<0.001$ & 1.00 & 1.00 & 1.00 & 1.000 \\
\hline Deformities in the thoracic wall & $<0.001$ & 1.00 & 1.00 & 1.00 & 1.000 \\
\hline \multicolumn{6}{|l|}{ Related factors } \\
\hline Position of the body inhibiting pulmonary expansion & -- & 1.00 & -- & -- & 1.000 \\
\hline Physical effort & $<0.001$ & 1.00 & 1.00 & 1.00 & 1.000 \\
\hline Anxiety & $<0.001$ & 1.00 & 0.05 & 1.00 & 0.972 \\
\hline Pain & -- & 1.00 & -- & -- & 1.000 \\
\hline \multicolumn{6}{|l|}{ Risk population } \\
\hline Age $<2$ years old & $<0.001$ & 0.05 & 0.05 & 0.05 & 0.003 \\
\hline Value *** & & $95 \%$ & & & value* \\
\hline 0.74 & & $5-0.90$ & & & 0.001 \\
\hline
\end{tabular}

Note: ${ }^{*}$ Shapiro-Wilk test ${ }^{* *}$ Wilcoxon test ${ }^{* * *}$ S statistics -- values that do not vary. 
Table 3 - Analysis by the evaluators of the relevance of the defining characteristics of the nursing diagnosis "Breathing Pattern, Ineffective" $(n=23)$, Fortaleza, Ceará, Brazil, 2019(2)

\begin{tabular}{|c|c|c|c|c|c|}
\hline \multirow{2}{*}{$\begin{array}{l}\text { Variables } \\
\text { Defining characteristics }\end{array}$} & \multicolumn{3}{|c|}{ Relevance } & & \multirow{2}{*}{ Value** } \\
\hline & $p$ value* & CVI & $\mathrm{Cl} 95 \%$ & & \\
\hline Use of accessory muscles for respiration & -- & 1.00 & -- & -- & 1.000 \\
\hline Alterations in the deepness of breath & -- & 1.00 & -- & -- & 1.000 \\
\hline Tachypnea & -- & 1.00 & -- & -- & 1.000 \\
\hline Changes in the respiratory rhythm & -- & 1.00 & -- & -- & 1.000 \\
\hline Dyspnea & -- & 1.00 & -- & -- & 1.000 \\
\hline Orthopnea & -- & 1.00 & -- & -- & 1.000 \\
\hline Hypoxia & -- & 1.00 & -- & -- & 1.000 \\
\hline Hypoxemia & -- & 1.00 & -- & -- & 1.000 \\
\hline Cyanosis & $<0.001$ & 1.00 & 1.00 & 1.00 & 1.000 \\
\hline Sleep-disordered breathing & $<0.001$ & 1.00 & 1.00 & 1.00 & 1.000 \\
\hline Fatigue of respiratory muscles & -- & 1.00 & -- & -- & 1.000 \\
\hline Assuming the three-point position & $<0.001$ & 1.00 & 1.00 & 1.00 & 1.000 \\
\hline Nose wing beating & $<0.001$ & 1.00 & 1.00 & 1.00 & 1.000 \\
\hline Bradypnea & -- & 1.00 & -- & -- & 1.000 \\
\hline Increased thoracic excursion & -- & 1.00 & -- & -- & 1.000 \\
\hline Breathing with frowned lips & $<0.001$ & 1.00 & 1.00 & 1.00 & 1.000 \\
\hline Diminished expiration pressure & $<0.001$ & 1.00 & 1.00 & 1.00 & 1.000 \\
\hline Diminished inspiration pressure & $<0.001$ & 1.00 & 1.00 & 1.00 & 1.000 \\
\hline Ventilation per minute diminished & -- & 1.00 & -- & -- & 1.000 \\
\hline Prolonged expiration stage & $<0.001$ & 1.00 & 1.00 & 1.00 & 1.000 \\
\hline $\begin{array}{l}\text { Increased anteroposterior diameter } \\
\text { Value }\end{array}$ & $\begin{array}{l}<\mathbf{0 . 0 0 1} \\
\mathrm{Cl} 95 \%\end{array}$ & 1.00 & 1.00 & $\begin{array}{c}1.00 \\
p \text { value* }\end{array}$ & 0.998 \\
\hline 0.85 & $0.77-0.93$ & & & $<0.001$ & \\
\hline
\end{tabular}

In the analysis of the relevance of the defining characteristics expressed in Table 3, the 21 defining characteristics indicated the $\mathrm{CVI}>0.9$, with statistically significant values: use of accessory muscles for breathing, changes in respiratory depth, tachypnea, changes in the respiratory rhythm, dyspnea, orthopnea, hypoxia, hypoxemia, cyanosis, sleep-disordered breathing, fatigue in accessory muscles, prolonged expiration stage, nose wing beating, bradypnea, altered thoracic excursion, ventilation per minute diminished, respiration with frowned lips, increased anteroposterior diameter, and assuming the three-point position ${ }^{(2)}$. These results show a high level of agreement $(S=0.85)$ among the classification of the evaluators.

\section{DISCUSSION}

The nursing diagnosis "Breathing Patter, Ineffective", was developed by NANDA-I taxonomy based on the knowledge of the physiology of the respiratory system and of the defects usually associated to this system ${ }^{(2)}$. Since then, researches have accumulated evidences for its validation through clinical validation studies ${ }^{(2)}$. These also show the need for further studies to clarify the inconsistencies found, clarify concepts, and facilitate their evaluation ${ }^{(4-6)}$.

In this work, $90 \%$ of the causal factors studied were validated, that is, in more than half the cases, the evidences found in literature were found to be relevant for the development of the BPI in the pediatric population with congenital heart defects. From the causal factors validated, three were already in the list of NANDA-I related factors: position of the body inhibiting pulmonary expansion; anxiety and pain; as well as the associated condition "deformity in the thoracic walls". Among the causal factors validated that are not yet listed in the NANDA-I, are the "physical effort", the conditions associated to the "increased resistance of air passages", "reduction in pulmonary complacency", "increased concentration of carbon dioxide", "increased concentration of hydrogen".

Regarding the causal factors submitted to the analysis of the evaluators, five of them were similar to previous studies that associated them to BPI in children with congenital heart defects ${ }^{(5-8)}$ : reduction in pulmonary complacency, increase in the resistance of air passages, physical effort, increased carbon dioxide concentration, and anxiety.

Several factors reinforce the relation between the associated condition "increased resistance in air passages" and the ND BPI in children with CHD, among which the following stand out: abnormal anatomic structures, high prevalence of lung hypertension and increased lung blood flow, in addition to recurring respiratory tract infections ${ }^{(17-21)}$. All these conditions contribute to make the passage of air more difficult, thus generating an increase in the resistance of air passages and impairing ventilation.

The reduction of pulmonary complacency was another associated condition that the evaluators in this study validated. This clinical condition, usually, shows itself in heart defects with left-to-right shunts (pulmonary hyperflux), leading to congestive cardiac failure due to increased atrial and ventricular pressure on the right side. This leads to the distension of pulmonary vases and alveoli, which, in turn, leads to pulmonary congestion ${ }^{(1,17-18,22-23)}$. Therefore, patients with this type of heart defect are expected to need an extra effort during respiration, as an adaptive response for the pulmonary expansion.

The associated conditions "increased carbon dioxide concentration" and "increased hydrogen ion concentration" take place both in the heart defects with a hypoflux (left-to-left shunt) and with those with pulmonary hyperflux. Both heart defects frequently generate ventilation perfusion mismatches in an attempt to compensate or correct the high levels of carbon dioxide and hydrogen ions, thus justifying their validity as components of causal factors $^{(1)}$.

Physical effort, despite the fact that it cannot be considered to be a clinical condition, was a related factor that the evaluators validated, since it influences the ventilation with the child in CHD, demanding an increase in the effort to breath and, thus, requiring the muscles to consume more oxygen, which in turn leads to a loss of respiratory muscle force due to the offer of oxygen in children with CHD to be limited ${ }^{(24)}$. Therefore, running, going up stairs, or walking (even for short distances) are actions that lead to the exacerbation of signs and symptoms that compromise the ventilation of children with congenital heart defects.

The risk population which was not seen as relevant was "Age below 2 years old". For most evaluators, the age of the child with a congenital heart defect could hardly increase their susceptibility for a BPI diagnostic, despite reports in literature according to which younger children are more susceptible to respiratory diseases due to their anatomic and physiological characteristics, such as smaller air passages, pulmonary immaturity, smaller alveolar surfaces, and immature immunological system ${ }^{(25)}$. 
Previous studies with children with congenital heart defects showed a high frequency in the development of the BPI diagnostic in children below 2 years old ${ }^{(5,8)}$. Although there are studies indicating possible associations between the BPI, no researches were found that investigated the cause-and-effect relations between the stimulus "age below 2 years old" and the diagnosis being studied. As a result, this risk population was excluded.

The confluence of the causal factors described leads to the establishment of a series of signs and symptoms (defining characteristics [DCs]) that form the nursing diagnosis BPI in children with congenital heart anomalies. It stands out that all DCs submitted to the evaluation of the evaluators reached a $\mathrm{CVI}<0.9$, that is, $100 \%$ of them were validated.

All 16 DCs that belonged to the list of signs and symptoms of BPI were validated. Corroborating this, 11 of these clinical indicators had already been validated in the target population of this study (comprised of children with congenital heart defects), among which: the use of accessory muscles for breathing, changes in respiratory depth, tachypnea, changes in the respiratory rhythm, dyspnea, orthopnea, nose wing beating, bradypnea, altered thoracic excursion, respiration with frowned lips, increased anteroposterior diameter, and assuming the three-point position ${ }^{(5)}$.

Five of the DCs validated by the specialists for the population of children with congenital heart defects are, as of yet, not a part of the list in the taxonomy of NANDA-I: hypoxemia, cyanosis, hypoxia, fatigue of the respiratory muscles, and sleep-disordered breathing. Corroborating this evidence, studies of content validity of the BPI in children with respiratory failure also validated the DCs "hypoxemia" and "cyanosis". However, as opposed to the results of this research, the DC "hypoxia" was not considered relevant for the evaluators of the studies mentioned, although being associated to pulmonary ventilation disorders ${ }^{(13,26)}$.

The DC "hypoxemia", in children with heart defects, is an important clinical sign of impaired ventilation, since it is the result of the deviation of the venous blood into the systemic circulation (a feature of cyanotic heart defects) and of the increase in the alveolocapillary diffusion, provoked by a liquid (pulmonary congestion) or by inflammatory processes (interstitial pneumonia). In those clinical conditions, which are common in children with CHD, there is no effective gas exchange in the alveolar level, leading to a diminution in the oxygenation of arterial blood ${ }^{(27)}$.

Cyanosis, on the other hand, is one of the clinical manifestations that suggest a framework of respiratory disturbances and makes up a sign of deficient oxygen transportation, despite not having any influence on this mechanism ${ }^{(28)}$.

Hypoxia is another DC that literature suggests, and this study validated it as a component that confirms the pulmonary ventilation impairment due to congenital heart anomalies. It stems from the insufficient oxygen intake for a certain metabolic rate that leads to an anaerobic metabolism, that is, an increased rate of lactate and a diminution in serum bicarbonate ${ }^{(29)}$.

On the other hand, the lack of coordination of respiratory movements causes respiratory fatigue, which is a DC evidenced by conditions that provoke inadequate ventilation. Although the NANDA-I classifies it as a related factor, this clinical manifestation develops whenever the supply rate is below the consumption level. When the energetic rate is unbalanced, such as in the misalignment between the cardiovascular function of congenital heart defects, the muscle does not generate the force expected ${ }^{(1)}$. As a result, this clinical indicator emerges from a causal factor, thus being a DC. This rationale is confirmed by the analysis of the evaluators.

Another validated DC was "sleep-disordered breathing". This clinical indicator is explained by the hemodynamic overload, which takes place in a specific stage of sleep called rapid eye movement (REM). It can contribute for the worsening of pulmonary congestion, making it easier for this DC to manifest ${ }^{(30)}$.

\section{Study limitations}

Among the limitations of this study, the rate of return of the instruments by the evaluators stand out (58.97\%). Another limitation was the use of a dichotomic scale to evaluate the relevance of the ND components. Another issue to observe is the scarcity of content validation of the BPI diagnosis, which made comparing and discussing the findings of this research more difficult.

\section{Contributions to the Field of Nursing}

The results presented contribute for the refinement and improvement of the diagnostic of $\mathrm{BPI}$ and its components ${ }^{(2)}$. As a result, this study is expected to contribute to increase the level of evidence of the diagnosis being addressed, in addition to aiding nurses to be able to identify more precisely the ND of BPI in their practice of care.

\section{CONCLUSION}

At first, a list with 10 causal factors and 21 DCs of the BPI diagnostic in children with congenital heart defects was submitted to the evaluators. From these, nine causal factors and all clinical indicators were validated.

The findings of this study include specific elements of the pediatric population with congenital heart defects that are not in the structure of the diagnostic of BPI, showing the need to expand its components. Therefore, the results of this investigation should be submitted to a clinical validation with the target population, to verify its relation and adequation to this diagnostic, as well as its preference in this specific clinical setting ${ }^{(2)}$.

\section{REFERENCES}

1. Apostolopoulou SC. The respiratory system in pediatric chronic heart disease. Pediatr Pulmonol. 2017;52(12):1628-35. https://doi. org/10.1002/ppul.23900

2. Souza NMG. Padrão respiratório ineficaz em crianças com cardiopatias congênitas: construção e validação por juízes de uma teoria de médio alcance[Dissertação]. Fortaleza: Faculdade de Farmácia, Odontologia e Enfermagem, Universidade Federal do Ceará: 2017. 165p. 
3. Herdman TH, Kamitsuru S. Nanda International Nursing Diagnoses: definitions and classification 2018-2020. 11 a Ed. Oxford: WileyBlackwell; 2018.

4. Silva VG, Pereira JMV, Figueiredo LS, Guimarães TCF, Cavalcanti ACD. Nursing diagnoses in children with congenital heart disease: cross mapping. Acta Paul Enferm. 2015;28(6):524-30. https://doi.org/10.1590/1982-0194201500088

5. Beltrão BA, Herdman TH, Pascoal LM, Chaves DBR, Silva VM, Lopes MV. Ineffective breathing pattern in children and adolescents with congenital heart disease: accuracy of defining characteristics. J Clin Nurs. 2015;24;2505-13. https://doi.org/10.1111/jocn.12838

6. Beltrão BA, Silva VM, Araujo TL, Lopes MVO. Clinical indicators of ineffective breathing pattern in children with congenital heart diseases. Int J Nurs Terminol Classific. 2011;22;4-12. https://doi.org/10.1111/j.1744-618X.2010.01169.x

7. Silva VM, Lopes MVO, Araujo TL, Beltrão BA. Operational definitions of outcome indicators related to ineffective breathing patterns in children with congenital heart disease. Heart Lung. 2011;40(3):e70-7. https://doi.org/10.1016/j.hrtlng.2010.12.002

8. Silva VM, Lopes MVO, Araujo TL, Beltrão BA. Diagnósticos enfermeros en niños con cardiopatías congénitas: diferencias por género y edad. Enferm Clin. 2011;21(4):214-8. http://dx.doi.org/ 10.1016/j.enfcli.2011.02.009

9. Lunney M. The need for international nursing diagnosis research and a theoretical framework. Int J Nurs Terminol Classif. 2008;19(1);28-3. https://doi.org/10.1111/j.1744-618X.2007.00076.x

10. Page SE. Making the difference: applying a logic of diversity. Acad Manag Perspect. 2007;21(4):6-20. https://doi.org/10.5465/amp.2007.27895335

11. Pasquali L, organizador. Instrumentos psicológicos: manual prático de elaboração. Brasília: LabPAM/IBAPP; 1999

12. Diniz CM, Lopes MVO, Nunes MM, Menezes AP, Silva VM, Leal LP. A content analysis of clinical indicators and etiological factors of ineffective infant feeding patterns. J Pediatr Nurs. 2020;50:5-13. https://doi.org/10.1016/j.pedn.2020.01.007

13. Pascoal LM, Lopes MVO, Silva VM, Diniz CM, et al. A Content Analysis of Clinical Indicators of the Nursing Diagnosis Ineffective Breathing Pattern. Int J Nurs Terminol Knowledge. 2020. https://doi.org/10.1111/2047-3095.12290

14. Benner P, Tanner C, Chesla C. Expertise in Nursing Practice: Caring, Clinical Judgment, and Ethics. Springer Publishing Company. 2009.

15. Simmons JP, Nelson LD, Galak J, Frederick S. Intuitive biases in choice versus estimation: Implications for the wisdom of crowds. J Consumer Res. 2011;38. https://doi.org/10.1086/658070

16. Falotico R, Quatto P. Fleiss' kappa statistic without paradoxes. Qual Quant. 2015;49:463-70. https://doi.org/10.1007/s11135-014-0003-1

17. Krieger EV, Leary PJ, Opotowsky AR. Pulmonary hypertension in congenital heart disease: beyond Eisenmenger Syndrome. Cardiol Clinics. 2015;33(4):599-609. https://doi.org/10.1016/j.ccl.2015.07.003

18. Van der Feen DE, Bartelds B, Boer RA, Berger RMF. Pulmonary arterial hypertension in congenital heart disease: translational opportunities to study the reversibility of pulmonary vascular disease. Europ Heart J. 2017;38(26):2034-41. https://doi.org/10.1093/eurheartj/ehx034

19. Sahan YÖ, Kılıçoğlu E, Tutar ZÜ. Evaluation of children with congenital heart disease hospitalized with the Diagnosis of Lower Respiratory Tract Infection. J Pediatr Res. 2018;5(1):32-6. https://doi.org/10.4274/jpr.90532

20. Pongiglione G, Possidoni A, Luzio Paparatti U. Incidence of respiratory disease during the first two years of life in children with hemodynamically significant congenital heart disease in italy: a retrospective study. Pediatr Cardiol. 2016;37:1581-9. https://doi. org/10.1007/s00246-016-1473-9

21. Ozyurt A, Narin N, Baykan A, Argun MM, Pamukcu O, Zararsiz G, et al. Efficacy of palivizumab prophylaxis among infants with congenital heart disease: a case control study. Pediatr Pulmonol. 2015;50:1025-32. https://doi.org/10.1002/ppul.23102

22. Shaddy RE, George AT, Jaecklin T. Systematic literature review on the incidence and prevalence of heart failure in children and adolescents. Pediatr Cardiol. 2018;39:415-36. https://doi.org/10.1007/s00246-017-1787-2

23. Bronicki RA, Domico M, Checchia PA, Kennedy CE, Akcan-Arikan A. The use of nesiritide in children with congenital heart disease pediatric critical care medicine. 2017;18(2):151-8. http://dx.doi.org/10.1097/PCC.0000000000000996

24. Voss C, Harris KC. Physical activity evaluation in children with congenital heart disease. Heart. 2017;103:1408-12. https://doi.org/10.1136/ heartjnl-2017-311340

25. Checchia PA, Paes B, Bont L. Defining the risk and associated morbidity and mortality of severe respiratory syncytial virus infection among infants with congenital heart disease. Infect Dis Ther. 2017;6:37- 56. https://doi.org/10.1007/s40121-016-0142-x

26. Pascoal LM, Lopes MV, Silva VM, Chaves DB. Clinical differention of respiratory Nursing Diagnoses among children with Acute respiratory infection. J Pediatr Nurs. 2016;31(1):85-91. https://doi.org/10.1016/j.pedn.2015.08.002

27. Kaskinen AK, Helve $\mathrm{O}$, Andersson $\mathrm{S}$. Chronic hypoxemia in children with congenital heart defect impairs airway epithelial sodium transport. Pediatr Crit Care Med. 2016;17(1):45-52. Available from: https://doi.org/10.1097/PCC.0000000000000568

28. McPhillips L, Kholwadwala D, Sison CP, Gruber D, Ojamaa K. A Novel brain injury biomarker correlates with cyanosis in infants with congenital heart disease. Pediatr Cardiol. 2019;40(3):546-53. https://doi.org/10.1007/s00246-018-2023-4

29. Naqvi N, Doughty VL, Starling L, et al. Hypoxic Challenge Testing (Fitness to Fly) in children with complex congenital heart disease. Heart. 2018;104:1333-8. https://doi.org/10.1136/heartjnl-2017-312753

30. Miles S, Ahmad W, Bailey A, Hatton R, Boyle A, Collins NF. Sleep-Disordered breathing in patients with pulmonary valve incompetence complicating congenital heart disease. Congenit Heart Dis. 2016;11:678-82. https://doi.org/10.1111/chd.12369 